\title{
INCIDENCIA ECONÓMICA DEL IMPACTO AMBIENTAL, DESECHOS SÓLIDOS, PROVINCIA EL ORO - ECUADOR
}

\section{ECONOMIC INCIDENCE OF THE ENVIRONMENTAL IMPACT, SOLID WASTE, EL ORO PROVINCE - ECUADOR}

\author{
José Alberto Vásquez Flores \\ Doctorando en Ciencias Contables y Empresariales. Universidad Nacional Mayor de San Marcos. \\ Correo: patricio9596@gmail.com (autor corresponsal).
}

[Recibido: 2016/11/15 Aceptado: 2017/02/16]

\section{RESUMEN}

El presente artículo esta dado a sustentar las políticas económicas y el impacto ambiental que causan los desechos sólidos que se produce en la Provincia de El Oro del Ecuador; se expresó como problemática principal: Qué políticas económicas han incidido en el impacto ambiental de los desechos sólidos de la Provincia de El Oro del Ecuador, período 2010 - 2013. La investigación fue mixta: "Aplicada" en la primera parte, luego "explicativa", "longitudinal" y finalmente "cuantitativa" y "correlacionada", de acuerdo a la finalidad de la misma. Los resultados hallados fueron: de los datos estadísticos aportado por los Gobiernos Autónomos Descentralizados (GAD) Municipales de los cantones de la provincia de El Oro, presentados en forma global, los gastos ejecutados fueron mayores a los ingresos obtenidos por la tasa de recolección de basura, lo que generó un subsidio del presupuesto general del estado por 10031 893,38 USD, es decir, se mantuvo un déficit presupuestario en el manejo de los desechos sólidos en un promedio del $41 \%$, conforme lo demuestra la gráfica №. 5 . En conclusión, se sustenta que es admisible bajar el riesgo del impacto ambiental negativo de la provincia, y que su impacto se convierta en positivo para el buen vivir.

\section{PALABRAS CLAVE}

Desechos, ecología, medio ambiente.

\begin{abstract}
The present article is given to support the economic policies and the environmental impact caused by the solid waste produced in the Province of El Oro of Ecuador. The main problem addressed: What economic policies have influenced the environmental impact of solid waste in El Oro Province of Ecuador, period 2010-2013. The research was mixed: "Applied" in the first part, then "explanatory", "Longitudinal" and finally "quantitative" and "correlated", according to the purpose. The results obtained were: from the statistical data provided by the Municipal Decentralized Autonomous Governments (GAD) of the cantons of the province of El Oro, presented in a global way, the expenses executed were greater than the revenues obtained by the garbage collection rate, which generated a subsidy of the general budget of the state for 10031893,38 USD, that is to say, a budget deficit was maintained in the management of the solid wastes in an average of $41 \%$, as demonstrated in graph No. 5 . In conclusion, it is argued that it is permissible to lower the risk of the negative environmental impact of the province, and that its impact becomes positive for good living.
\end{abstract}

\section{KEYWORDS}

Waste, ecology, environment.

Como Citar: Vásquez, J. (2017). Incidencia económica del impacto ambiental, desechos sólidos, provincia El Oro - Ecuador Quipukamayoc, 25(48), 39-47. doi: http://dx.doi.org/10.15381/quipu.v25i48.13990 


\section{INTRODUCCIÓN}

En pleno siglo XXI ha comenzado una impronta catastrófica de desastres ecológicos y naturales sin precedentes en la historia mundial. Uno de los impactos mayores constatados por los científicos es el cambio ambiental global. (De la Cuadra Arancibia, 2013, pág. 33).

El análisis trata de la importancia que tiene el impacto ambiental con lo socio económico de un país, región, provincia y cantón, para el caso nuestro particular hemos tomado como referencia la provincia de El Oro, ubicado al sur de la República del Ecuador, haciendo frontera con el norte del Perú.

El aspecto relevante en nuestro estudio, tiene que ver con la incidencia económica del impacto ambiental de los desechos sólidos de la provincia de El Oro de la república del Ecuador, tomando como referencia los presupuestos institucionales de los Gobiernos Autónomos Descentralizados de las provincias, analizando si los recursos destinados al plan del manejo ambiental con respecto a los residuos sólidos son suficientes para cubrir la demanda de los desechos que produce la ciudadanía y sus empresas, permitiendo garantizar a vivir en un ambiente sano.

Aspectos que lograran determinar: en qué medida las leyes, regulaciones económicas, subsidios, impuestos, e inversiones que se realicen para conservar el medio ambiente, inciden minimizar el deterioro causado por los desechos sólidos que produce la ciudadanía y sus empresas en la provincia de El Oro de la República del Ecuador.

El objetivo general es: identificar las principales políticas económicas y como han incidido en el impacto ambiental de los desechos sólidos de la provincia de El Oro del Ecuador, período 2010 - 2013.

El estudio se circunscribe a los Gobiernos Autónomos Descentralizados Municipales y Delegación Provincial de El Oro de la Contraloría General del Estado de la República del Ecuador por el periodo 2010 - 2013.

Según Onofrio (2012) refiere que a través de la investigación se ha apretado los nuevos movimientos socio-ambientales con los discursos de protesta social en la crisis del 2001. La defensa de éstos movimientos están encaminadas a que el Estado no ceda ante los capitales de la empresas sin que éstos presenten un plan de manejo ambiental y de remediación.

\section{Características de los lixiviados}

Espinoza (2007) menciona que los líquidos lixiviados resultantes de la descomposición de cuerpos sepultados bajo suelo, estos se caracterizan por ser soluciones acuosas ricas en sales minerales y sustancias orgánicas degradables, de color castaño-aceitunado, más viscosas que el agua, polimerabisables, de olor fuerte y pronunciado, con elevado grado de toxicidad y patogenicidad, bastante soluble en agua a un $\mathrm{pH}$ entre 5 a 9 y temperatura de $23^{\circ} \mathrm{C}$ a $28^{\circ} \mathrm{C}$. Su nivel de toxicidad depende de la presencia de compuestos orgánicos y de la carga viral patogénica del cuerpo inhumado.

Chung (2003) menciona que la eliminación de los residuos sólidos constituye desde hace mucho tiempo un gran problema para la sociedad; en el caso de los residuos sólidos urbanos el primer eslabón de la cadena empieza desde el momento en que el habitante de la zona se preocupa solamente en deshacerse de ellos, sin preocuparse en lo más mínimo el destino que le espera y en las consecuencias que traerá al medio ambiente; el siguiente eslabón lo constituyen las municipalidades al no impulsar programas alternativos de gestión de residuos sólidos.

Maldonado (2009) refiere que los problemas de la contaminación ambiental, se dan por la explosión demográfica no controlada, el crecimiento industrial no partidario con el ambiente, al inadecuado manejo de los desechos sólidos e infecciosos, a la evacuación de las aguas residuales, a las lluvias ácidas, el calentamiento global y pérdida de la capa de ozono, todo esto desequilibra al ecosistema.

De igual manera Yauli (2012) manifiesta: que la eliminación de los residuos sólidos municipales, hasta los años 70 la gran parte de los desechos sólidos se los botaba en basureros a cielo abierto, los desperdicios se quemaban para reducir el volumen y alargar la vida de los sitios, pero la basura no se quema de manera ideal, los botaderos ardientes producen nubarrones que se ven a kilómetros, esto provoca malos olores y crean un cultivo de moscas y ratas, en los basureros a cielo abierto al no ser controlados los incineradores, constituyen también fuentes de contaminación.

En tanto Ávila (2013) sostiene que el mundo utiliza para su diario vivir genera residuos de todo orden; lo que comúnmente se denomina basura, que si no se trata correctamente, genera otros problemas, tales como: contaminación del agua, suelo y aire; además, producción de moscas; dispersión de enfermedades y en fin toda gama de males que la humanidad ha tenido que endosarse a lo largo del tiempo.

\section{Características del estudio de impacto ambiental}

El Estudio de Impacto Ambiental (EIA) es un documento técnico de carácter interdisciplinario destinado 
a predecir, identificar, valorar y considerar medidas preventivas o corregir las consecuencias que determinadas acciones antrópicas pueden causar sobre la calidad de vida del hombre y su entorno (Coria, 2008).

Su finalidad es que la autoridad respectiva decida respecto a la conveniencia ambiental y social de la generación de nuevos proyectos en un determinado ámbito geográfico.

Conessa (2006) refiere que el EIA, está conformado por una serie de análisis, estudios y descripciones, que le permiten a la autoridad realizar una estimación de los impactos positivos y negativos, teniendo en su entorno inmediato, tareas previstas para mitigar efectos negativos y un plan de monito-

\section{Tabla 1.}

reo para evaluar la situación real con el emprendimiento en función.

\section{MATERIAL Y MÉTODOS}

Es una investigación longitudinal, se mueve entre los años 2010 y 2013. Retrospectiva porque veremos los efectos de lo realizado por la actividad productiva propia en la provincia de El Oro. Las fuentes son secundarias y primarias, acudimos a datos del Presupuesto Público, Gobiernos Autónomos Descentralizados Provincial y Municipales y otros entes económicos. Evidentemente es una investigación aplicada a un caso real y es libre (Montes, 2012).

Es una investigación cuantitativa, porque buscó medir los efectos eco- nómicos del impacto ambiental que producen los desechos sólidos en los cantones de la provincia de El Oro de la República del Ecuador (Medina, 2001).

Es una investigación aplicada en la primera parte, luego explicativa, longitudinal y finalmente "cuantitativa" y "correlacionada", de acuerdo a la finalidad de la misma.

\section{RESULTADOS}

Los resultados de la investigación, sirve como herramienta interesante para que los Gobiernos Autónomos Descentralizados Municipales de la provincia de El Oro determinen sobre qué aspectos de los residuos sólidos debe fortalecer el control ambiental.

Presupuesto ejecutado para manejo de residuos sólidos para el año 2010.

Fuente: Presupuestos de los GAD Municipales de la provincia de El Oro.

\begin{tabular}{|c|c|c|c|c|}
\hline \multirow{2}{*}{$\begin{array}{c}\text { GAD } \\
\text { Municipal de los cantones de la } \\
\text { provincia de El Oro }\end{array}$} & \multicolumn{2}{|c|}{ Presupuesto ejecutado 2010} & \multirow{2}{*}{$\begin{array}{l}\text { Diferencia cubierta de las } \\
\text { asignaciones fiscales }\end{array}$} & \multirow[b]{2}{*}{$\%$} \\
\hline & $\begin{array}{l}\text { Ingresos por la tasa de } \\
\text { recolección de basura }\end{array}$ & Gastos & & \\
\hline Arenillas & 141950,00 & 141950,00 & 0,00 & $0 \%$ \\
\hline Atahualpa & 125465,00 & 125465,00 & 0,00 & $0 \%$ \\
\hline Chilla & 124750,00 & 124750,00 & 0,00 & $0 \%$ \\
\hline El Guabo & 151450,00 & 151450,00 & 0,00 & $0 \%$ \\
\hline Huaquillas & 163250,00 & 163250,00 & 0,00 & $0 \%$ \\
\hline Las Lajas & 150890,00 & 150890,00 & 0,00 & $0 \%$ \\
\hline Machala & 681774,43 & 745384,57 & 63610,14 & $9 \%$ \\
\hline $\begin{array}{l}\text { Marcabeli y Balsas (MARBAL } \\
\text { EP) }\end{array}$ & 64990,00 & 64990,00 & 0,00 & $0 \%$ \\
\hline Pasaje & 470865,40 & 850420,20 & 379554,80 & $81 \%$ \\
\hline Piñas & 510320,00 & 1020350,00 & 510030,00 & $100 \%$ \\
\hline Portovelo & 180320,00 & 180320,00 & 0,00 & $0 \%$ \\
\hline Santa Rosa & 485530,00 & 715350,00 & 229820,00 & $47 \%$ \\
\hline Zaruma & 420025,00 & 750085,00 & 330060,00 & $79 \%$ \\
\hline Total & 3671579,83 & 5184654,77 & 1513074,94 & $41 \%$ \\
\hline
\end{tabular}

De los datos estadísticos aportado por los Gobiernos Autónomos Descentralizados (GAD) Municipales de los cantones de la provincia de El Oro del Ecuador, se puede apreciar que los in- gresos ascienden a 3671 579,83 USD y los gastos a 51844654,77 USD, por lo que, los gastos ejecutados son mayores a los ingresos obtenidos por la tasa de recolección de basura, gene- rándose un subsidio del presupuesto general del estado por 1513 074,94,80 USD, es decir, que en el año 2010 existió un déficit presupuestario en el manejo de los desechos sólidos del $41 \%$. 


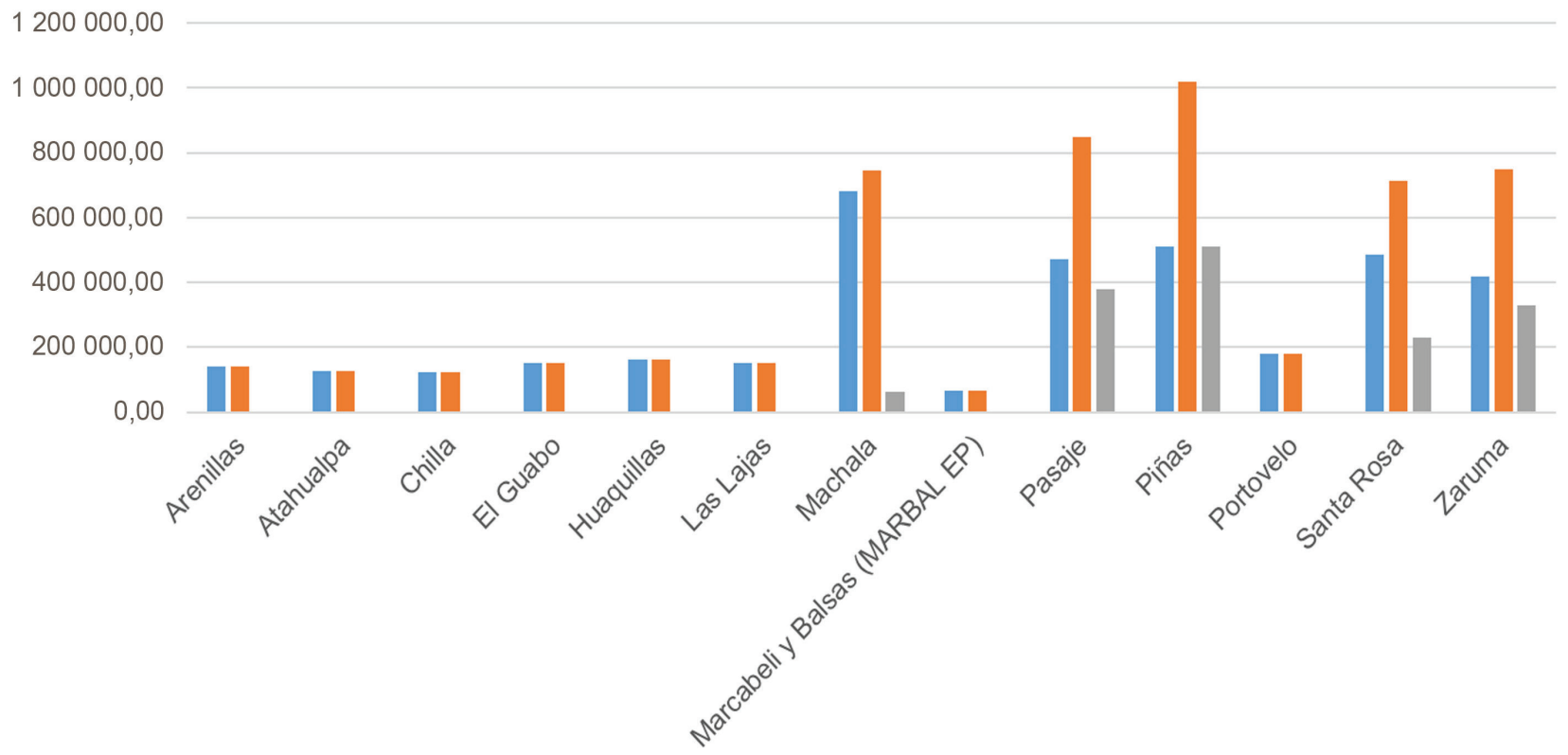

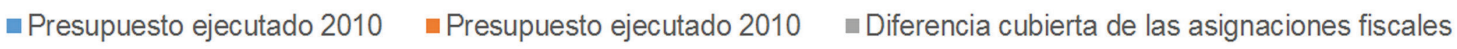

Figura 1. Presupuesto ejecutado para manejo de residuos sólidos para el año 2010.

Fuente: Presupuestos de los GAD Municipales de la provincia de El Oro. / Elaboración propia.

\section{Tabla 2.}

Presupuesto ejecutado para manejo de residuos sólidos para el año 2011

Fuente: Presupuestos de los GAD Municipales de la provincia de El Oro.

\begin{tabular}{|c|c|c|c|c|}
\hline \multirow{2}{*}{$\begin{array}{c}\text { GAD } \\
\text { Municipal de los cantones de la } \\
\text { provincia de El Oro }\end{array}$} & \multicolumn{2}{|c|}{ Presupuesto ejecutado 2011} & \multirow[b]{2}{*}{$\begin{array}{l}\text { Diferencia cubierta de las } \\
\text { asignaciones fiscales }\end{array}$} & \multirow[b]{2}{*}{$\%$} \\
\hline & $\begin{array}{l}\text { Ingresos por la tasa de } \\
\text { recolección de basura }\end{array}$ & Gastos & & \\
\hline Arenillas & 145950,00 & 215350,00 & 69400,00 & $48 \%$ \\
\hline Atahualpa & 145465,00 & 202650,00 & 57185,00 & $39 \%$ \\
\hline Chilla & 164750,00 & 210355,00 & 45605,00 & $28 \%$ \\
\hline El Guabo & 150540,00 & 315025,00 & 164485,00 & $109 \%$ \\
\hline Huaquillas & 170250,00 & 312650,00 & 142400,00 & $84 \%$ \\
\hline Las Lajas & 180890,00 & 205325,00 & 24435,00 & $14 \%$ \\
\hline Machala & 2338933,51 & 2557158,02 & 218224,51 & $9 \%$ \\
\hline Marcabeli y Balsas (MARBAL EP) & 44000,00 & 44000,00 & 0,00 & $0 \%$ \\
\hline Pasaje & 510865,25 & 850560,45 & 339695,20 & $66 \%$ \\
\hline Piñas & 610320,00 & 1120350,00 & 510030,00 & $84 \%$ \\
\hline Portovelo & 280320,00 & 280320,00 & 0,00 & $0 \%$ \\
\hline Santa Rosa & 685530,00 & 850775,00 & 165245,00 & $24 \%$ \\
\hline Zaruma & 520025,00 & 950085,00 & 430060,00 & $87 \%$ \\
\hline Total & 5947838,76 & 8114603,47 & 2166764,71 & $36 \%$ \\
\hline
\end{tabular}


De los datos estadísticos aportado por los GAD Municipales de los cantones de la provincia de El Oro del Ecuador, se puede apreciar que los ingresos ascienden a 5947838,76 USD y los gas- tos a 8114603,47 USD, por lo que, los gastos ejecutados son mayores a los ingresos obtenidos por la tasa de recolección de basura, generándose un subsidio del presupuesto general del estado por 2166764,71 USD, es decir, que en el año 2011 existió un déficit presupuestario en el manejo de los desechos sólidos del $36 \%$.

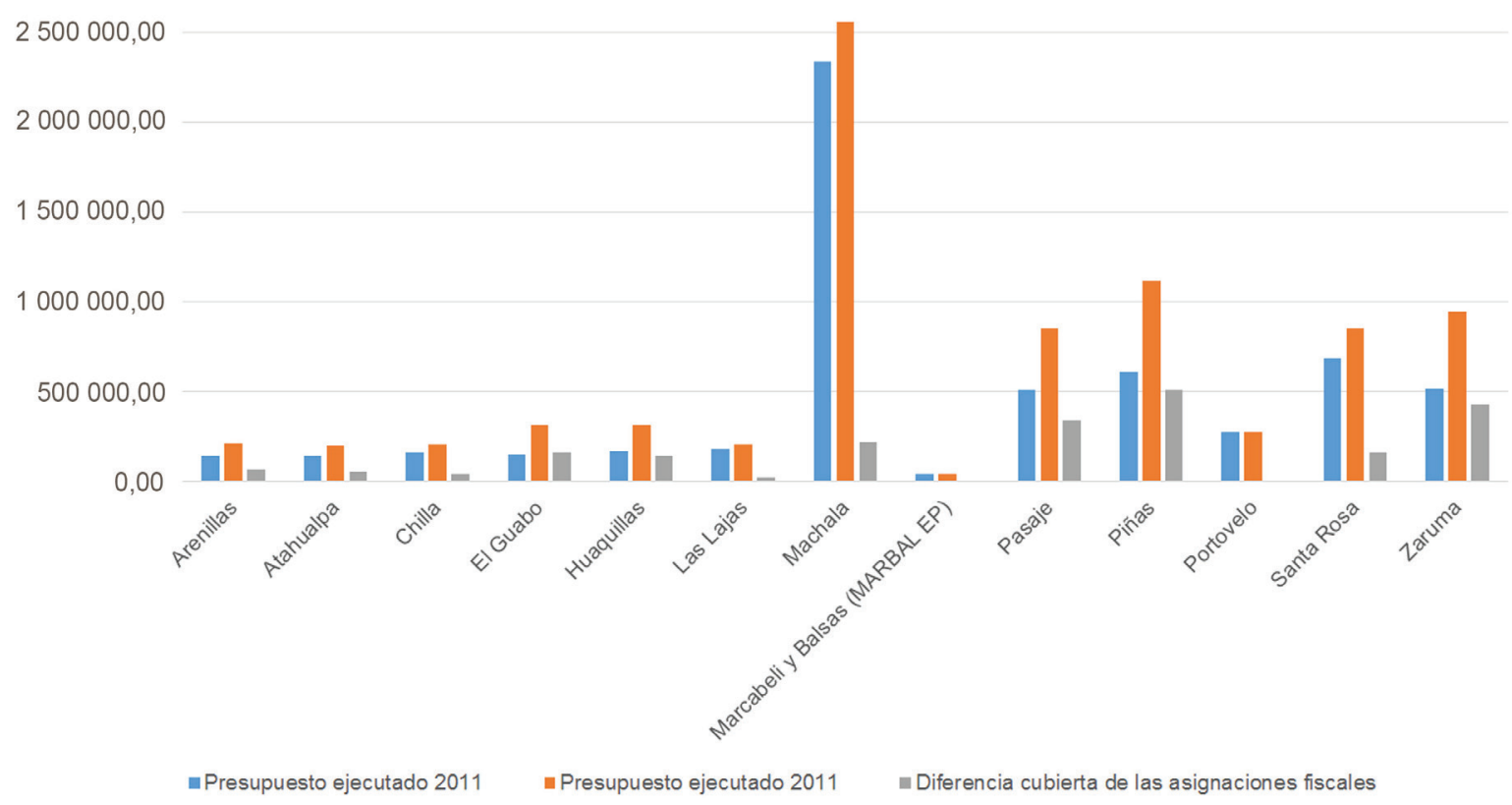

Figura 2. Presupuesto ejecutado para manejo de residuos sólidos para el año 2011.

Fuente: Presupuestos de los GAD Municipales de la provincia de El Oro. / Elaboración propia.

Tabla 3.

Presupuesto ejecutado para manejo de residuos sólidos para el año 2012 Fuente: Presupuestos de los GAD Municipales de la provincia de El Oro.

\begin{tabular}{lrrrrr}
\multicolumn{1}{c}{$\begin{array}{c}\text { Gunicipal de los cantones de la } \\
\text { provincia de El Oro }\end{array}$} & $\begin{array}{c}\text { Presupuesto ejecutado 2012 } \\
\text { Ingresos por la tasa de } \\
\text { recolección de basura }\end{array}$ & Gastos & $\begin{array}{c}\text { Diferencia cubierta de las } \\
\text { asignaciones fiscales }\end{array}$ & \% \\
Arenillas & 165950,00 & 255350,00 & 89400,00 & $54 \%$ \\
\hline Atahualpa & 185465,00 & 285340,00 & 99875,00 & $54 \%$ \\
\hline Chilla & 184610,00 & 210355,00 & 25745,00 & $14 \%$ \\
\hline El Guabo & 155340,29 & 155340,29 & 0,00 & $0 \%$ \\
\hline Huaquillas & 270250,00 & 392650,00 & 122400,00 & $45 \%$ \\
\hline Las Lajas & 280890,00 & 305325,00 & 24435,00 & $9 \%$ \\
\hline Machala & 2522862,33 & 3271515,55 & 748653,22 & $30 \%$ \\
\hline Marcabeli y Balsas (MARBAL EP) & 127771,44 & 123267,91 & $-4503,53$ & $-4 \%$ \\
\hline Pasaje & 570765,24 & 854416,10 & 283650,86 & $50 \%$ \\
\hline Piñas & 650320,00 & 1180350,00 & 530030,00 & $82 \%$ \\
\hline Portovelo & 380320,00 & 550765,00 & 170445,00 & $45 \%$ \\
\hline Santa Rosa & 785530,00 & 975775,00 & 190245,00 & $24 \%$ \\
\hline Zaruma & 620025,00 & 980085,00 & 360060,00 & $58 \%$ \\
\hline Total & 6900099,30 & 9540534,85 & 2640435,55 & $38 \%$
\end{tabular}


De los datos estadísticos aportado por los GAD Municipales de los cantones de la provincia de El Oro del Ecuador, se puede apreciar que los ingresos ascienden a 6900 099,30 USD y los gas- tos a 9540534,85 USD, por lo que, los gastos ejecutados son mayores a los ingresos obtenidos por la tasa de recolección de basura, generándose un subsidio del presupuesto general del estado por 2640 435,55 USD, es decir, que en el año 2012 existió un déficit presupuestario en el manejo de los desechos sólidos del 38\%.

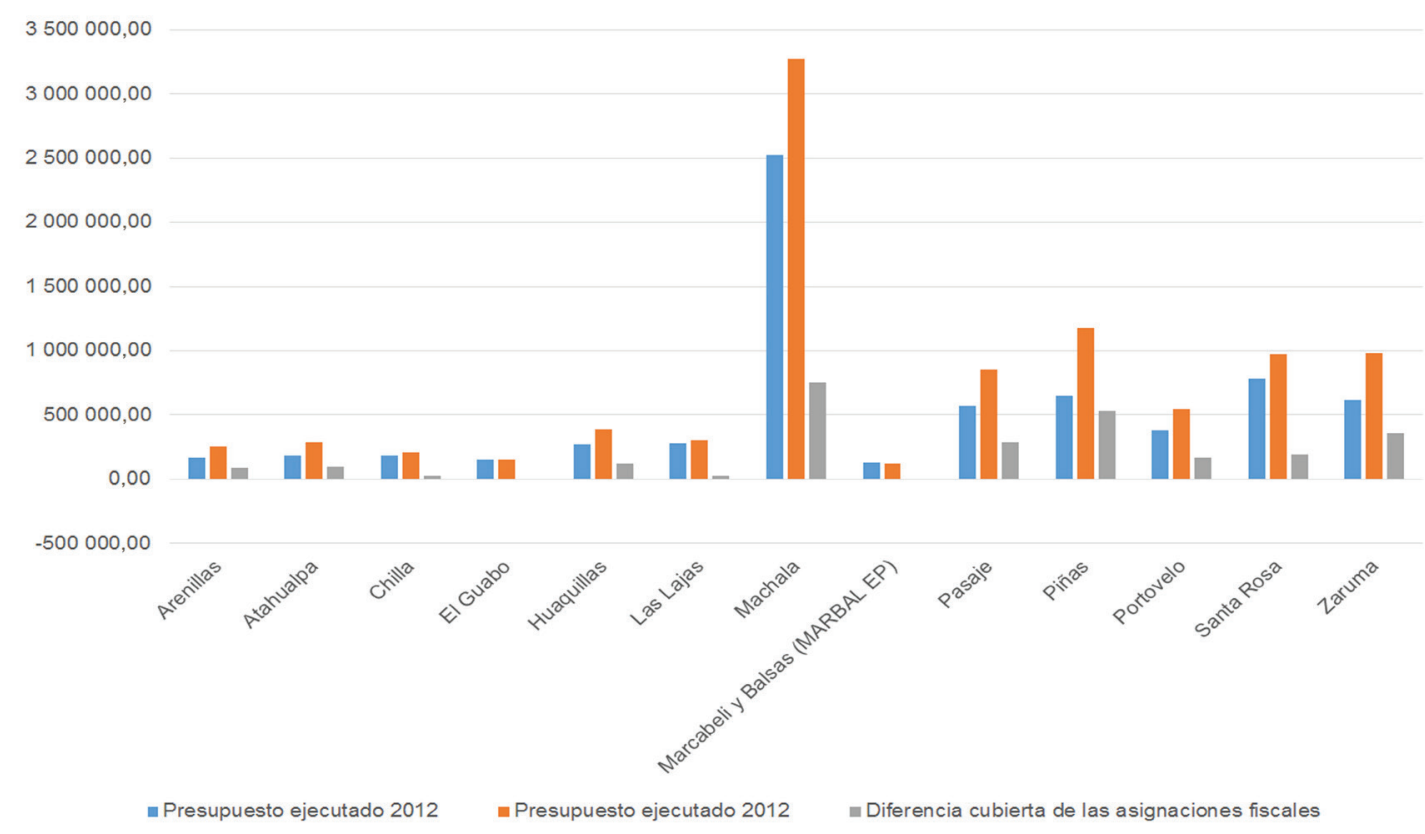

Figura 3. Presupuesto ejecutado para manejo de residuos sólidos para el año 2012.

Fuente: Presupuestos de los GAD Municipales de la provincia de El Oro. / Elaboración propia.

Tabla 4.

Presupuesto ejecutado para manejo de residuos sólidos para el año 2013

Fuente: Presupuestos de los GAD Municipales de la provincia de El Oro.

\begin{tabular}{|c|c|c|c|c|}
\hline \multirow{2}{*}{$\begin{array}{c}\text { GAD } \\
\text { Municipal de los cantones de la } \\
\text { provincia de El Oro }\end{array}$} & \multicolumn{2}{|c|}{ Presupuesto ejecutado 2013} & \multirow{2}{*}{$\begin{array}{l}\text { Diferencia cubierta de las } \\
\text { asignaciones fiscales }\end{array}$} & \multirow[b]{2}{*}{$\%$} \\
\hline & $\begin{array}{l}\text { Ingresos por la tasa de } \\
\text { recolección de basura }\end{array}$ & Gastos & & \\
\hline Arenillas & 265950,00 & 365350,00 & 99400,00 & $37 \%$ \\
\hline Atahualpa & 285465,00 & 395340,00 & 109875,00 & $38 \%$ \\
\hline Chilla & 284610,00 & 340355,00 & 55745,00 & $20 \%$ \\
\hline El Guabo & 167946,72 & 415165,00 & 247218,28 & $147 \%$ \\
\hline Huaquillas & 370250,00 & 592650,00 & 222400,00 & $60 \%$ \\
\hline Las Lajas & 380890,00 & 405325,00 & 24435,00 & $6 \%$ \\
\hline Machala & 2664870,59 & 3773382,88 & 1108512,29 & $42 \%$ \\
\hline Marcabeli y Balsas (MARBAL EP) & 213535,23 & 214603,98 & 1068,75 & $1 \%$ \\
\hline Pasaje & 629637,24 & 854416,10 & 224778,86 & $36 \%$ \\
\hline Piñas & 640320,00 & 1205950,00 & 565630,00 & $88 \%$ \\
\hline Portovelo & 388520,00 & 650765,00 & 262245,00 & $67 \%$ \\
\hline Santa Rosa & 715925,00 & 1075775,00 & 359850,00 & $50 \%$ \\
\hline Zaruma & 650525,00 & 1080985,00 & 430460,00 & $66 \%$ \\
\hline Total & 7658444,78 & 11370062,96 & 3711618,18 & $48 \%$ \\
\hline
\end{tabular}


De los datos estadísticos aportado por los GAD Municipales de los cantones de la provincia de El Oro del Ecuador, se puede apreciar que los ingresos ascienden a 7658444,78 USD y los gas- tos a 11370 062,96 USD, por lo que, los gastos ejecutados son mayores a los ingresos obtenidos por la tasa de recolección de basura, generándose un subsidio del presupuesto general del estado por 3711618,18 USD, es decir, que en el año 2013 existió un déficit presupuestario en el manejo de los desechos sólidos del $48 \%$.

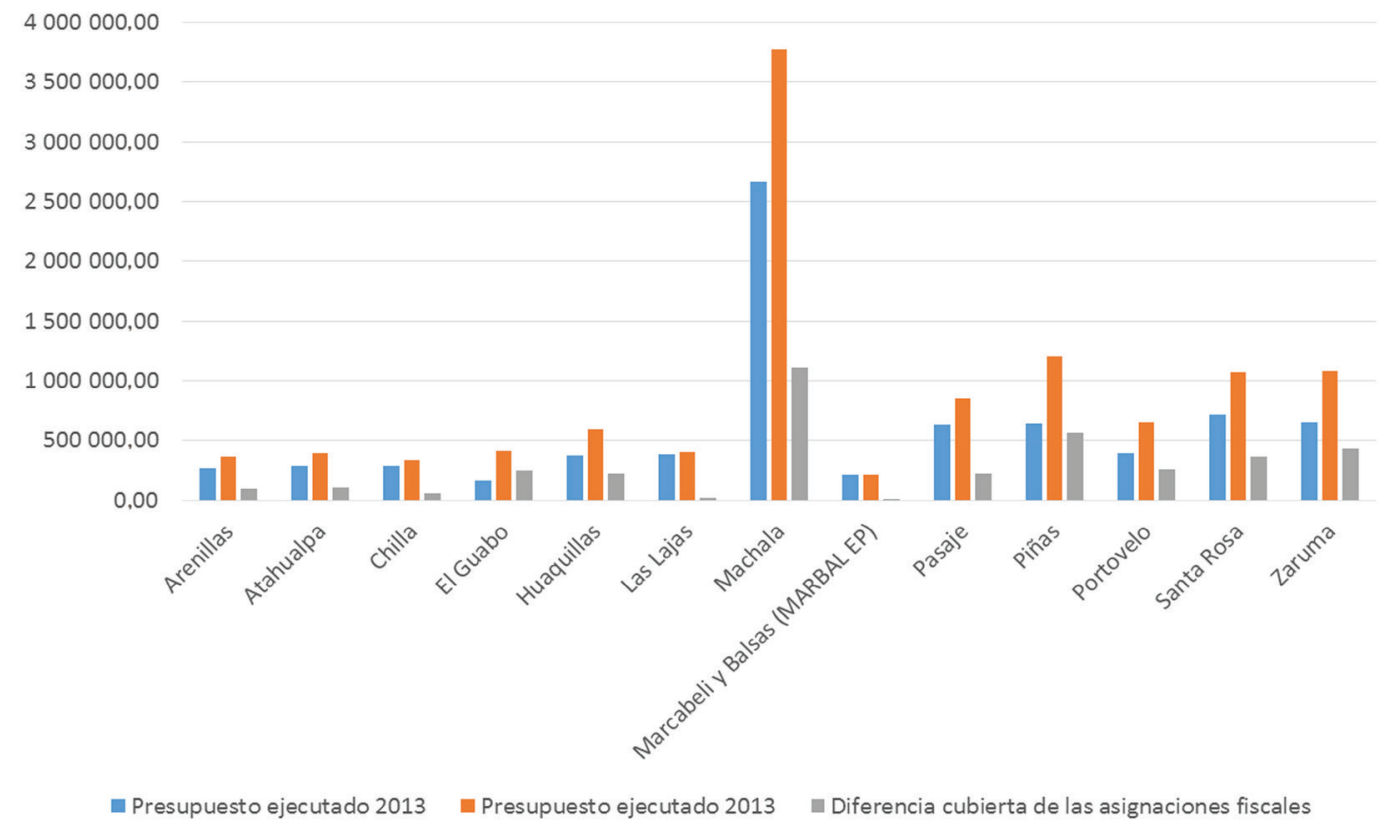

Figura 4. Presupuesto ejecutado para manejo de residuos sólidos para el año 2013.

Fuente: Presupuestos de los GAD Municipales de la provincia de El Oro. / Elaboración propia.

Tabla 5.

Presupuesto ejecutado para manejo de residuos sólidos para los años 2010 - 2013

Fuente: Presupuestos de los GAD Municipales de la provincia de El Oro.

\begin{tabular}{lrrrrr}
\multicolumn{1}{c}{$\begin{array}{c}\text { GAD } \\
\text { punicipal de los cantones de la } \\
\text { provincia de El Oro }\end{array}$} & $\begin{array}{c}\text { Presupuesto ejecutado 2010 - 2013 } \\
\text { Ingresos por la tasa de } \\
\text { recolección de basura }\end{array}$ & Gastos & $\begin{array}{c}\text { Diferencia cubierta de las } \\
\text { asignaciones fiscales }\end{array}$ & \% \\
Arenillas & 719800,00 & 978000,00 & 258200,00 & $36 \%$ \\
\hline Atahualpa & 741860,00 & 1008795,00 & 266935,00 & $36 \%$ \\
\hline Chilla & 758720,00 & 885815,00 & 127095,00 & $17 \%$ \\
\hline El Guabo & 625277,01 & 1036980,29 & 411703,28 & $66 \%$ \\
\hline Huaquillas & 974000,00 & 1461200,00 & 487200,00 & $50 \%$ \\
\hline Las Lajas & 993560,00 & 1066865,00 & 73305,00 & $7 \%$ \\
\hline Machala & 8208440,86 & 10347441,02 & 2139000,16 & $26 \%$ \\
\hline Marcabeli y Balsas (MARBAL EP) & 450296,67 & 446861,89 & $-3434,78$ & $-1 \%$ \\
\hline Pasaje & 2182133,13 & 3409812,85 & 1227679,72 & $56 \%$ \\
\hline Piñas & 2411280,00 & 4527000,00 & 2115720,00 & $88 \%$ \\
\hline Portovelo & 1229480,00 & 1662170,00 & 432690,00 & $35 \%$ \\
\hline Santa Rosa & 2672515,00 & 3617675,00 & 945160,00 & $35 \%$ \\
\hline Zaruma & 2210600,00 & 3761240,00 & 1550640,00 & $70 \%$ \\
\hline Total & 24177962,67 & 34209856,05 & 10031893,38 & $41 \%$
\end{tabular}


Del análisis global del 2010 al 2013, se puede apreciar que los ingresos ascienden a 24177 962,67 USD y los gastos a 34209856,05 USD, siendo en resumen los gastos ejecutados mayores a los ingresos obtenidos por la tasa de recolección de basura, generándose un subsidio del presupuesto general del estado por 10031 893,38 USD, es decir, se ha mantenido un déficit presupuestario en el manejo de los desechos sólidos en un promedio del $41 \%$.

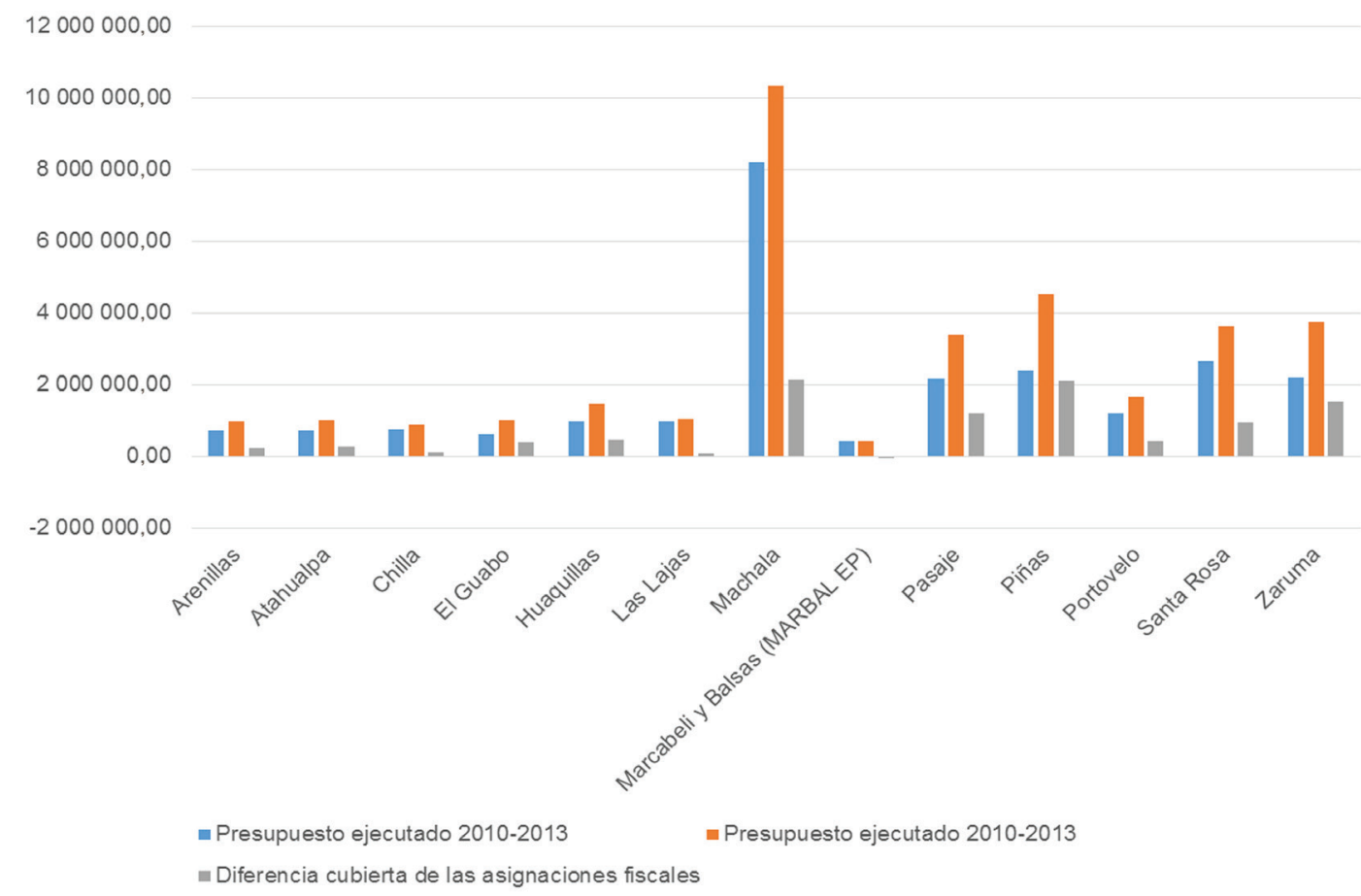

Figura 4. Presupuesto ejecutado para manejo de residuos sólidos para los años 2010 - 2013.

Fuente: Presupuestos de los GAD Municipales de la provincia de El Oro. / Elaboración propia.

Se realizó el tratamiento estadístico, se llevó dos tipos de resultados; el primer resultado está dado en un conjunto de tablas y gráficos con respecto a los ingresos y gastos que ejecutaron los Gobiernos Autónomos Descentralizados (GAD) Municipales de los cantones de la provincia de El Oro del Ecuador en los períodos 2010, 2011, 2012 y 2013; y, el segundo resultado está basado en la evidencia de la muestra y en las teorías de las probabilidades, usado para determinar si una afirmación es o no es razonable, describiéndolas en leyes, regulaciones económicas, subsidios e impuestos.

\section{DISCUSIÓN}

En la medida que las Leyes que se dan en el ámbito económico para conservar el medio ambiente sean las adecuadas permitirán minimizar su de- terioro por los desechos sólidos de la Provincia de El Oro del Ecuador, período 2010 - 2013 No son necesarias las comillas. Los resultados en los cuadros 6 y 11 muestran que si las leyes son adecuadas en el ámbito económico, probablemente permitirán bajar el riesgo del impacto ambiental negativo de la provincia, porque el error estándar de la proporcionalidad es del $2 \%$, teniendo su probabilidad alta del $98 \%$ en reducir el deterioro que producen los residuos sólidos.

Si las Regulaciones económicas que se dan para conservar el medio ambiente son claras incidirán en minimizar el deterioro ambiental por los desechos sólidos de la Provincia de El Oro del Ecuador, período 2010 - 2013. Los resultados en los cuadros 7 y 12 muestran que si las regulaciones eco- nómicas que se dan para conservar el medio ambiente sean claras, probablemente permitirán minimizar el riesgo del impacto ambiental negativo de la provincia, al tener un error estándar de la proporcionalidad del $2 \%$, tenemos una probabilidad alta del $98 \%$ de reducir el deterioro que producen los residuos sólidos.

Si los Subsidios que se aplican para conservar el medio ambiente son coherentes influirán favorablemente en minimizar el deterioro ambiental por los desechos sólidos de la Provincia de El Oro del Ecuador, período 2010 - 2013. Los resultados en los cuadros 8 y 13 muestran que si los subsidios fueran coherentes, éstas influirían favorablemente del impacto ambiental negativo de la provincia, al tener un error estándar de la proporcionalidad 
del $9 \%$, teniendo probabilidades alta del $91 \%$ de minimizar el deterioro ambiental que producen los desechos sólidos.

Si los Impuestos orientados a la conservación del medio ambiente se aplican de manera integral entonces permitirán minimizar el deterioro ambiental por los desechos sólidos de la Provincia de El Oro del Ecuador, período 2010 - 2013. Los resultados en los cuadros 9 y 14 muestran que si los impuestos orientados a conservar el medio ambiente se aplicaran de manera integral en el manejo de los desechos sólidos, permitirían minimizar el riesgo del impacto ambiental negativo de la provincia, al tener un error estándar de la proporcionalidad del $3 \%$, tenemos una probabilidad alta del 97\% de reducir el deterioro que producen los residuos sólidos.

Las principales políticas económicas y como inciden en el impacto ambiental de los desechos sólidos de la provincia de El Oro del Ecuador, período 2010 2013. Podemos afirmar que, existe correlación positiva de incidencia entre las políticas económicas y el impacto ambiental causados por los residuos sólidos.

Las principales Leyes que se dan en el ámbito económico para conservar el medio ambiente permiten minimizar su deterioro por los desechos sólidos de la Provincia de El Oro del Ecuador, período 2010 - 2013. Podemos afirmar que, las leyes en el ámbito económico existe correlación positiva para conservar el medio ambiente, reduciendo el riesgo que causan los residuos sólidos que produce la provincia.

Las Regulaciones económicas que se establecen para conservar el medio ambiente inciden en minimizar el deterioro ambiental por los desechos sólidos de la Provincia de El Oro del Ecuador, período 2010 - 2013. Pode- mos afirmar que, las regulaciones económicas tienen correlación positiva para conservar el medio ambiente, reduciendo el riesgo que causan los residuos sólidos que produce la provincia.

Los subsidios que se aplican para conservar el medio ambiente influyen en minimizar el deterioro ambiental por los desechos sólidos de la Provincia de El Oro del Ecuador, período 2010 2013. Podemos afirmar que, no existe correlación entre los subsidios y el impacto ambiental para reducir el riesgo que causan los residuos sólidos que produce la provincia.

Los Impuestos orientados a la conservación del medio ambiente permiten minimizar el deterioro ambiental por los desechos sólidos de la Provincia de El Oro del Ecuador, período 2010 2013. Podemos afirmar que, existe correlación positiva entre los impuestos y el impacto ambiental para reducir el riesgo que causan los residuos sólidos que produce la provincia.

\section{REFERENCIAS BIBLIOGRÁFICAS}

Ávila, D. (2013). Propuesta para el manejo integral de los desechos sólidos de la población urbana del cantón Nabón. (Tesis de maestría). Universidad Politécnica Salesiana, Guayaquil.

Chung, A. (2003). Análisis económico de la ampliación de la cobertura del manejo de residuos sólidos por medio de la segregación en la fuente en Lima Cercado. (Tesis de maestría). Universidad Nacional Mayor de San Marcos, Lima.

Conessa, V. (2006). Guía metodológica para la evaluación del impacto ambiental. Madrid: Mundi-Prensa.

Coria, I. (2008). El estudio de impacto ambiental: características y metodologías. Invenio, 11(20), 125-135. Obtenido de http://www.redalyc.org/articulo.oa? id $=87702010$
De la Cuadra, F. (2013). Desarrollo, crisis ambiental y pueblos originarios en América Latina. Espacio Regional, 2(10), 33-49. Obtenido de https://dialnet.unirioja.es/servlet/ articulo? codigo $=4743371$

Espinoza, J. (2007). Contaminación de aguas subterráneas por lixiviados provenientes de sepulturas bajo suelo en el campo santo "Parque del Paraíso" Lurín - Lima. (Tesis de maestría). Universidad Nacional Mayor de San Marcos, Lima. Recuperado de http:// cybertesis.unmsm.edu.pe/bitstream/ cybertesis/373/1/Espinoza_ej.pdf

Maldonado, J. (2009). Ciudades y contaminación ambiental. Revista de Ingeniería, (30), 66-71. Obtenido de http://www.redalyc.org/articulo. oa?id=121015710002

Medina, C. (2001). Paradigmas de la investigación sobre lo cuantitativo y cualitativo. Ciencia e Ingeniería, (10), pp. 79-84. Obtenido de http://www. redalyc.org/articulo.oa? $\mathrm{id}=91101010$

Montes, I. (2012). Investigación longitudinal de los hábitos de estudio en una cohorte de alumnos universitarios. Revista Lasallista de Investigación, 9(1), 96-116. Obtenido de http://www.redalyc.org/articulo. oa?id=69524955005

Onofrio, S. (2012). Educación para el desarrollo sostenible. París: Organización de la Naciones Unidas.

Yauli, A. (2012). Manual para el Manejo de Desechos Sólidos en la Unidad Educativa Darío Guevara, Parroquia Cunchibamba, Cantón Ambato, Provincia de Tungurahua. (Tesis de Licenciatura). Repositorio Institucional de la Escuela Superior Politécnica de Chimborazo, Chimborazo, Ecuador. Recuperado de http://dspace.espoch. edu.ec/handle/123456789/1298 